Volume 10. No.2, February 2022

International Journal of Emerging Trends in Engineering Research

Available Online at http://www.warse.org/IJETER/static/pdf/file/ijeter161022022.pdf

https://doi.org/10.30534/ijeter/2022/161022022

\title{
Application of Artificial Neural Networks Technology for Handwritten Arabic Letters Recognition
}

\author{
Aisha Douma ${ }^{1}$, Abdussalam Ali Ahmed ${ }^{2}$, Abdulgader Alsharif ${ }^{3}$, Mohamed Belrzaeg ${ }^{4}$ \\ ${ }^{1}$ Department of Computer Engineering, Atilim University, Ankara, Turkey, aishaalwerfally@yahoo.com \\ ${ }^{2}$ Mechanical and Industrial Engineering Department, Bani Waleed University, Bani Waleed/Libya, \\ abdussalam.a.ahmed@gmail.com \\ ${ }^{3}$ College of Civil Aviation Technology and Meteorology, Espiaa, Libya, abdelkaderalsharif@gmail.com \\ ${ }^{4}$ College of Applied Sciences and Technology, Al-Awata, Libya, mohamed.alrazgi86@gmail.com
}

Received Date : January 04, 2022 Accepted Date : January 30, 2022 Published Date : February 07, 2022

\begin{abstract}
The mechanism that convert and detect the handwriting letters by using machine-encoded forms is called handwriting recognition. The interaction between machines and humans is very important so that the handwriting recognition must be found. The complexity of Arabic letters and the similarity of at least three letters is main challenge to recognize them .Thus, our main challenge is to propose a methodology, implementation and evaluation of Arabic letters recognition system by using Artificial Neural Network approach in order to achieve high accuracy with some techniques will be produced in this paper.

In this paper, we apply recognition artificial neural network (ANN) for Arabic letters. We use the intensity values of pixels for input of the neural network. These results show that ANN with high number of training images have the highest performace.
\end{abstract}

Key words: Artificial Neural Networks, Arabic letters, Recognition, Matlab.

\section{INTRODUCTION}

The Arabic script has similar characteristics to the Hebrew alphabet. It is an Abjad consonantal system and some letters are short and long vowels. Abjad means consonant alphabet, or consonants with some vowels letters. Most of Abjad language scripts are written from right to left like Arabic language. The consonant letters in Arabic are 25 letters while the vowels letters are "أ", "و", the Arabic language used as an Abjad and as an alphabet.

Arabic writing language is a bound and cursive script, rather than a succession of individual letters. In addition to other consequences, this implies that the form of the letter is influenced by the position it occupies in the word. An Arabic word is written from right to left, not capitalized, and the division of the word over lines is not allowed. On the other hand, it is possible to lengthen the lines that join letters as much as needed, to achieve the intended format. The double consonants are indicated with a tashdid, (a symbol similar to the ' $w$ ') above the letter in question.

In addition to Arabic, there are several languages that use this same alphabet, which include Urdu and Persian.

Character recognition is an application of pattern recognition discipline. For decades, much work has been done with computers to make the patterns of words easier to distinguish. Some of the patterns studied are characters, symbols, pictures, three-dimensional physical objects, sound waves, electrocardiograms, and seismic waves. A detailed and comprehensive survey of this topic was found in [1][2][3]. The Arabic letter " in its different forms is shown in Figure 1.

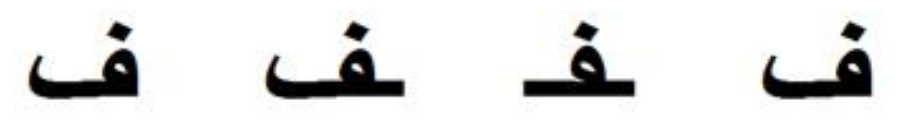

Figure1: The Arabic letter " ف in its different forms. In the beginning, middle, end, isolated - from right to left.

\section{ARTIFICIAL NEURAL NETWORK (ANN)}

The artificial neural network has same idea of the human brain, it gains knowledge through repetition of training and save this knowledge by using the connecting forces within neurons known as weights.

A neurobiological similarity presents an opportunity for biologists to rely on ANN to understand the evolution of natural phenomena. Neurons are the basis of neural networks in the human brain.

As shown in Figure 2, a neural network of human brain consists of four parts that form dendrites, axons, nuclei, and connections[4]. 


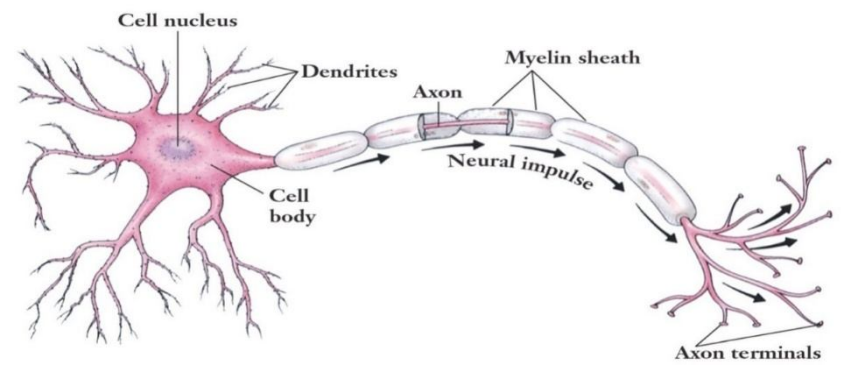

Figure 2: The construction of neuron.

Here, the same theqniue of the network of neurons is used in Artificial neural network, on computer we create the neurons artificially. Many neurons which made artificially are connecting as an Artificial neural network.

The structure of an artificial neural network is consists of:

$>$ The inputs $\mathrm{X}_{1}, \mathrm{X}_{2}, \ldots . . \mathrm{X}_{\mathrm{n}}$. They can be float, an integer ....etc

$>$ Weights: $\mathrm{W}_{1}, \mathrm{~W}_{2}, \mathrm{~W} 3, \ldots \ldots . \mathrm{W}_{\mathrm{n}}$

$>$ Adder to collect signals in the weighted income.

$>$ Activation function $(\sigma)$ : the usage of this function is to limit the output of the neuron where it makes the output within the field $[0,1]$ or within the field $[-1,1]$.

$>$ Output (Y) [5].

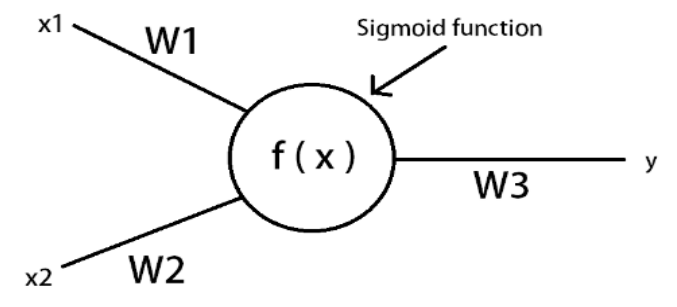

Figure 3: The structure of an artificial neural network [6].

The feed forward back-propagation neural network with two hidden layers was used to update the weights from output layer return back to hidden layer then input layer to achieve best accuracy. The first hidden layer with 13 nodes and the second layer of one node we used for the output layer as shown in Figure 4.

The algorithm was tested on a multiple scenario with different numbers of neurons in layers. The system was trained and evaluated with printed text, as well as several different handwriting images provided by eight people the results showed reduced performance in recognizing printed text when differentiating between more than 1120 letters.

The 900 features are used for input to the neural network. These 900 features are obtained of each pixel of input image. In this simulation, each figure has $30 \times 30$ pixels.

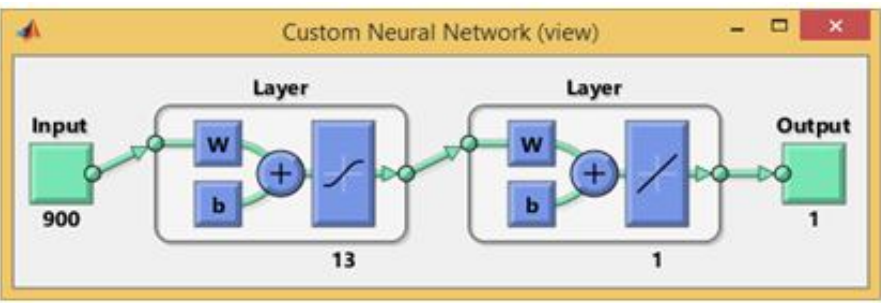

Figure 4: Architecture of the proposed neural network.

\section{METHODOLOGY}

\section{Flowchart}

The flowchart in figure 5 consists the steps of methodology of artificial neural network method. As we mentioned before we gave eight people to write all the Arabic alphabet from (i to ), they wrote each letter 10 times after that by using scanner device, we captured all the letters to obtain 2240 images. Then converted these images into PNG format and segment them by same size (image resizing) which means all the images have same pixel dimension to give same features numbers of process and increase the accuracy that leads to reduce the time.

Then extracting the features of the images image by image is the most important part of handwriting recognition.

The forth step was classification; we used the artificial neural network classifier on ANN algorithm.

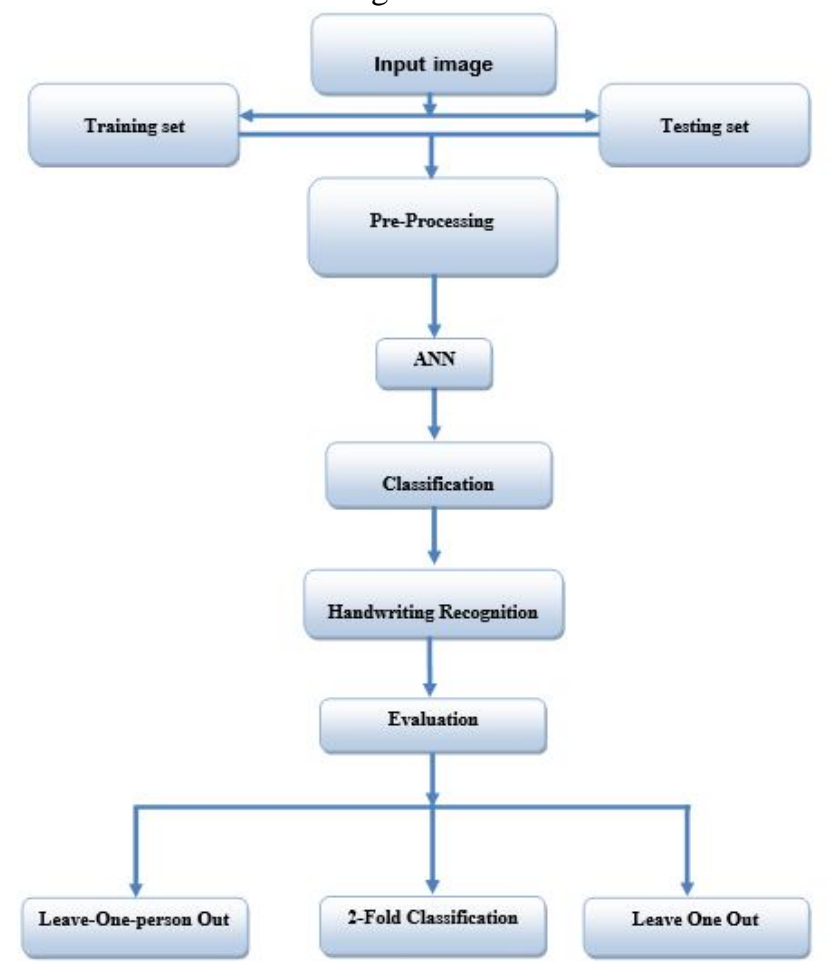

Figure 5: The methodology of ANN handwriting recognition. 
Lastly, we evaluate the results of images by using leave one person out, 2-fold classification and last technique is leave one out approach. A sample of the proposed dataset is shown in Figure 6.

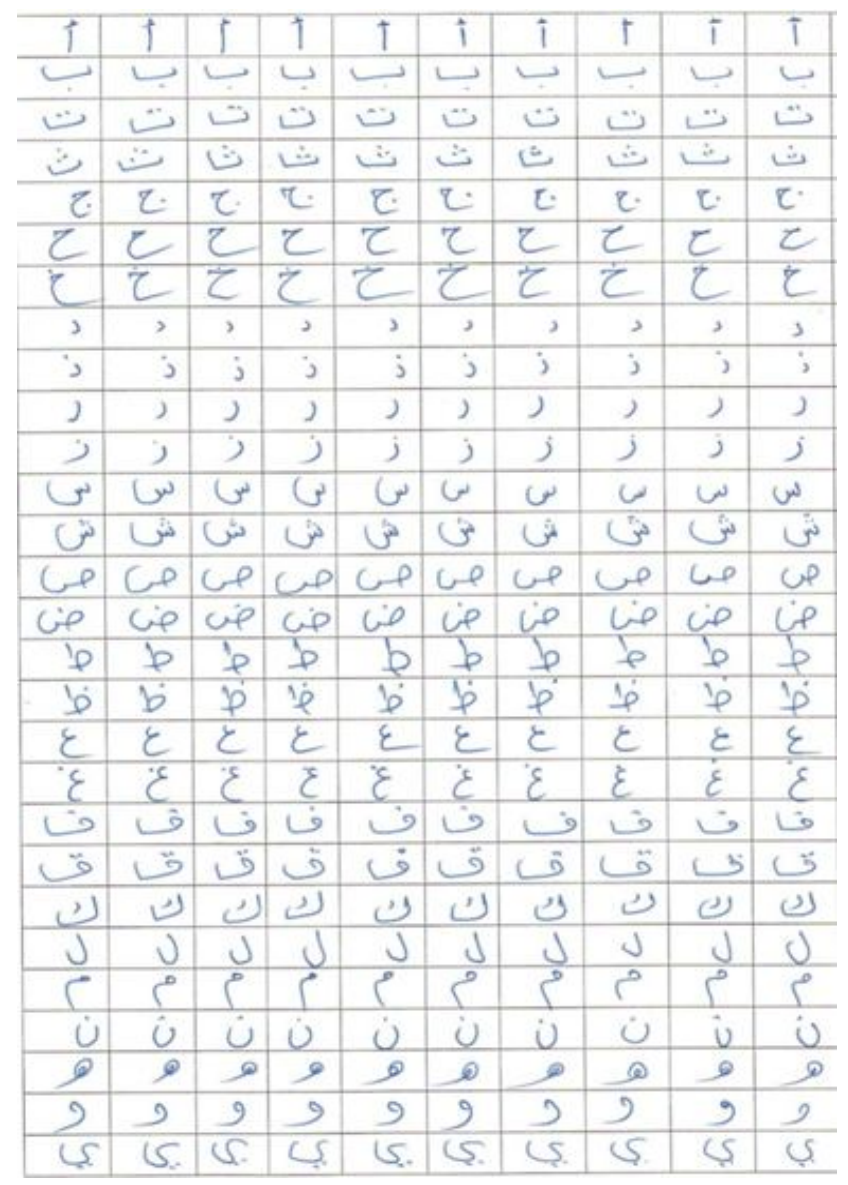

Figure 6: A Sample of database.

For the simulation results, the dataset that we collect totally consists of 2240 images, (8-person x 10 times $x$ 28letter). This dataset is used into two cases; the first one we use 1120 images while the second case we use the total number of 2240 images (the final number of images that were handwritten. In the case of 1120 images, 840 images are used for training and the rest of images equal 280 for testing. The other case is 2240 images; we used 1960 images for training and the rest for test. The all images are read and processed from database regularly. That means the input of images it was regular input, image by image for all people from people 1 to 8 .

\section{RESULTS}

The output result of artificial neural network by using the half of the total number of images (1120 imges), the result is $57.9 \%$. All the letters is detected many times in this figure forexample, the second letter in Arabic alphapet also in this figure was detected 9 times, no letters detected correctly 10 times also no letters is detected zero of times.
In the figure 8 the lines 2, 11 and 24 are detected correctly 10 times. The detection of the other letters is not detected correctly. As we see the detection was in line 27 which is ' 9 ' letter in arabic alphabet. It was detected 2 times of 10 .

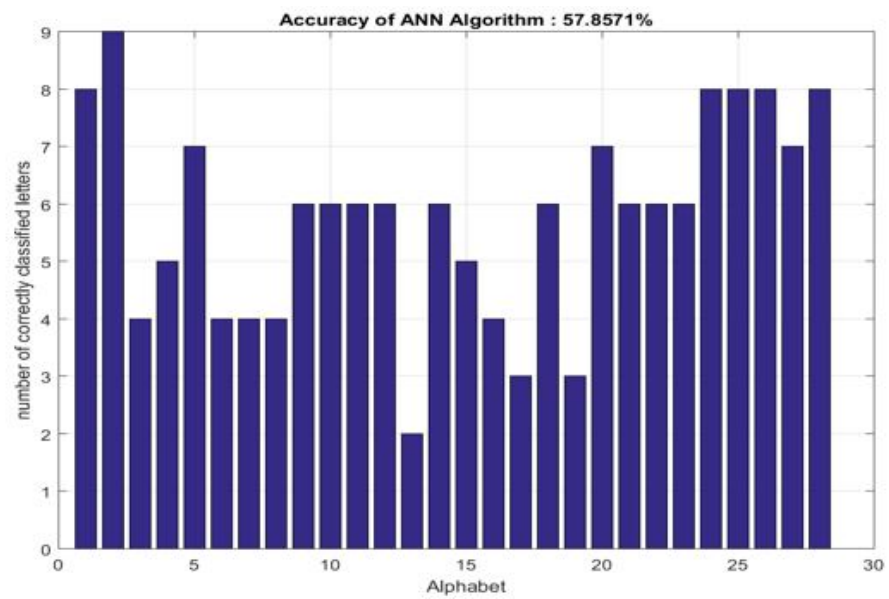

Figure 7: The result of ANN with 1120 images.

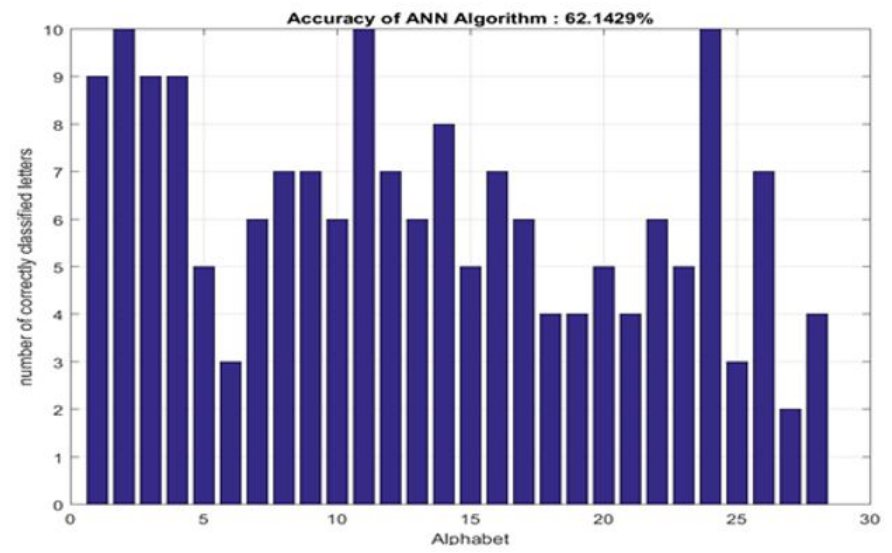

Figure 8: The result of ANN with 2240 images.

\section{RESULTS OF K-FOLD CLASSIFICATION}

The leave one person out approach means all the images for the first person are used in test and the other all images of the seven people are used in train. After that same processing for the second person and so on for the rest 6 people. Table 1 shows the performance of leave-one-person out approach and the average between all results was taken (48.1\%).

Table 1: Leave-one-person out approach with ANN

\begin{tabular}{|l|c|c|c|c|c|}
\hline Method & $\begin{array}{c}\text { Person 1 } \\
\text { \% }\end{array}$ & $\begin{array}{c}\text { Person } \\
\text { 2 \% }\end{array}$ & $\begin{array}{c}\text { Person } \\
\mathbf{3 \%}\end{array}$ & $\begin{array}{c}\text { Person } \\
\mathbf{4} \%\end{array}$ & \\
\hline ANN & 51.1 & 41.4 & 62.1 & 54.2 & \\
\hline Method & $\begin{array}{c}\text { Person } \\
\mathbf{5 \%}\end{array}$ & $\begin{array}{c}\text { Person } \\
\mathbf{6 \%}\end{array}$ & $\begin{array}{c}\text { Person } \\
\mathbf{7 \%}\end{array}$ & $\begin{array}{c}\text { Person } \\
\mathbf{8 \%}\end{array}$ & $\begin{array}{c}\text { Averag } \\
\text { e } \\
\mathbf{\%}\end{array}$ \\
\hline ANN & 51.6 & 35.0 & 41.1 & 47.9 & 48.1 \\
\hline
\end{tabular}


Aisha Douma et al., International Journal of Emerging Trends in Engineering Research, 10(2), February 2022, 123 - 127

The 2-Fold classification means the $50 \%$ of dataset is used in training (1120 images), and the other of $50 \%$ of data is used in training. The performance of the Artificial neural network with 2 -fold cassification is shown as below in table 2 .

Table 2: 2-Fold classification with ANN

\begin{tabular}{|c|c|}
\hline Method & Performance \% \\
\hline ANN & 63.3 \\
\hline
\end{tabular}

The holding of one image for testing, and use all other images for training is called leave-one-out technique. This technique produced high result for the proposed method because of the huge number of training data. The performance of ANN back propagation with leave one out is shown in Table 3.

Table 3: Leave-one-out cross with ANN

\begin{tabular}{|c|c|}
\hline Method & Performance \% \\
\hline ANN & 72.9 \\
\hline
\end{tabular}

As a summary to this paper: In table 4 the all results that we test of 1120 images ,2240 images, leave-one-person out, 2 fold classification and leave-one-out approach are showed below, That leads to' while the number of training images in increase, the performance will be high.

Table 4: The performance of K-Fold classification

\begin{tabular}{|c|c|c|c|}
\hline Algorithm & $\begin{array}{c}(40 \times 28)= \\
1120 \text { images } \\
840 \text { for } \\
\text { training } \\
280 \text { for } \\
\text { testing } \\
\end{array}$ & $\begin{array}{c}(80 x 28) \\
=2240 \text { images } \\
1960 \text { for } \\
\text { training } \\
280 \text { for } \\
\text { testing } \\
\end{array}$ & $\begin{array}{c}\text { leave-one-person } \\
\text { out performance } \\
\%\end{array}$ \\
\hline ANN & $57.9 \%$ & $62.1 \%$ & 48.1 \\
\hline Algorithm & $\begin{array}{c}\text { 2-Fold } \\
\text { classificatio } \\
\mathbf{n} \\
\text { performanc } \\
\text { e } \\
\% \\
\end{array}$ & $\begin{array}{c}\text { leave-one-out } \\
\text { performance } \\
\%\end{array}$ & \\
\hline ANN & 63.3 & 72.9 & \\
\hline
\end{tabular}

\section{CONCLUSION}

Handwriting Arabic letters is still needed a lot of interest, to minimize much errors depending with the design of handwriting language itself. In addition, the recognition of the pictures that not related with written text and select it as a picture still open question. With 2240 images, the accuracy of ANN was good and very close to ANN with 1120 images. Increasing the numbers of training samples may lead to an increase in the accuracy of letters recognition. In the developed system, the performance of the proposed method with leave one out technique is better than other techniques.

\section{REFERENCES}

1. A. Eleyan and H. Demirel, "Co-occurrence matrix and its statistical features as a new approach for face recognition," Turkish Journal of Electrical Engineering \& Computer Sciences, vol. 19, pp. 97-107, 2011.

2. M. Yazdi and K. Gheysari, "A new approach for the fingerprint classification based on gray-level co-occurrence matrix," International Journal of Computer and Information Science and Engineering, vol. 2, pp. 171-174, 2008.

3. R. Mokni and M. Kherallah, "Palmprint identification using GLCM texture features extraction and SVM classifier," Journal of Information Assurance \& Security, vol. 11, 2016.

4. https://www.haikudeck.com/motor-neuron-science-a nd-technology-presentation-PEvJXFhuPn.

5. http://physiol.gu.se/maberg/images.html.

6. N. P. T. Kishna and S. Francis, "Intelligent tool for Malayalam cursive handwritten character recognition using artificial neural network and Hidden Markov Model," 2017 International Conference on Inventive Computing and Informatics (ICICI), 2017, pp. 595-598, doi: 10.1109/ICICI.2017.8365201.

7. N. B. Muppalaneni, "Handwritten Telugu Compound Character Prediction using Convolutional Neural Network," 2020 International Conference on Emerging Trends in Information Technology and Engineering (ic-ETITE), 2020, pp. 1-4, doi: 10.1109/ic-ETITE47903.2020.349.

8. G. Ramesh, G. N. Sharma, J. M. Balaji and H. N. Champa, "Offline Kannada Handwritten Character Recognition Using Convolutional Neural Networks," 2019 IEEE International WIE Conference on Electrical and Computer Engineering (WIECON-ECE), 2019, pp. 1-5, doi: 10.1109/WIECON-ECE48653.2019.9019914.

9. Gao Daqi, Xie Chao and Nie Guiping, "Combinative neural-network-based classifiers for optical handwritten character and letter recognition," Proceedings of the International Joint Conference on Neural Networks, 2003., 2003, pp. 2232-2237 vol.3, doi: 10.1109/IJCNN.2003.1223757.

10. A. Douma, G. Şengül, F. G. Ibrahim Salem and A. Ali Ahmed, "Applying the Histogram of Oriented Gradients to Recognize Arabic Letters," 2021 IEEE 1st International Maghreb Meeting of the Conference on Sciences and Techniques of Automatic Control and Computer Engineering MI-STA, 2021, pp. 350-355, doi: 10.1109/MI-STA52233.2021.9464499.

11. A. Douma, A. A. Ahmed, G. Şengül, J. Santhosh, O. S. M. Jomah and F. G. Ibrahim Salem, "A comparison of Pattern Recognition Approaches for 
Aisha Douma et al., International Journal of Emerging Trends in Engineering Research, 10(2), February 2022, 123 - 127

Recognizing Handwriting in Arabic Letters," 2021

IEEE 1st International Maghreb Meeting of the Conference on Sciences and Techniques of Automatic Control and Computer Engineering MI-STA, 2021, pp. 818-824, doi: 10.1109/MI-STA52233.2021.9464483.

12. M. Hamdani, A. E. Mousa and H. Ney, "Open Vocabulary Arabic Handwriting Recognition Using Morphological Decomposition," 2013 12th International Conference on Document Analysis and Recognition, 2013, pp. 280-284, doi: 10.1109/ICDAR.2013.63.

13. A. Graves, M. Liwicki, S. Fernández, R. Bertolami, H. Bunke and J. Schmidhuber, "A Novel Connectionist System for Unconstrained Handwriting Recognition," in IEEE Transactions on Pattern Analysis and Machine Intelligence, vol. 31, no. 5, pp. 855-868, May 2009, doi: 10.1109/TPAMI.2008.137. 